\title{
THE EFFECT OF MELATONIN AND HYALURONIC ACID MIXTURE ON HARD TISSUE DIMENSIONAL CHANGES AROUND IMMEDIATE POST-EXTRACTION IMPLANTS. "RANDOMIZED CLINICAL TRIAL"
}

\author{
Azza Nasr", Mona Darhous**, Mona Shoeib ${ }^{* *}$ and Ahmed El Barbary***
}

\begin{abstract}
Background: Both melatonin (MLT) and Hyaluronic acid (HA) are widely used in the dental field especially in implant therapy due to their well known physiochemical properties and biologic effects that boost hard and soft tissues healing.
\end{abstract}

Aim: Assessing the effect of local application of a mixture of HA and MLT to the implant surface and peri-implant gap in immediate implants.

Subjects and Methods: Twenty-four subjects with teeth scheduled for extraction of hopeless teeth in the inter-bicuspid region were equally divided between test group (immediate implant with HA and MLT mixture) and a control group (immediate implant alone). CBCT scans were done immediately after implant placement and 6 months postoperatively to evaluate the bone changes in terms of vertical, horizontal bone dimensional and density changes.

Results: At the end of the study, the peri-implant vertical and horizontal buccal bone changes in test group recorded lower mean value compared to control group with no statistical significant difference between both groups with mean for test group $(-0.97 \pm 0.265 ;-0.33 \pm 0.222)$ and control group $(-1.08 \pm 0.275 ;-0.41 \pm 0.371)(\mathrm{p}=0.329 ; \mathrm{p}=0.543)$ respectively. As for the increase in bone density, there was a statistical difference between both groups in favor of the test group, with median and range [58.45 (8 - 110), $18.1(0-70)]$ for test and control groups respectively.

Conclusions: Within the limitations of this study, topical application of MLT and HA mixture might have a beneficial impact on immediate implant placement specifically in reduction of buccolingual dimensional changes and increasing bone density.

KEYWORDS: Melatonin, Hyaluronic Acid, Immediate implant, Dimensional changes

\footnotetext{
* Lecturer Oral Medicine and Periodontology Department, Faculty of Dentistry, Ahram Canadian University ** Professor Oral Medicine and Periodontology Department, Faculty of Dentistry, Cairo University

*** Assistant professor Oral Medicine and Periodontology Department, Faculty of Dentistry, Cairo University
} 


\section{INTRODUCTION}

Dental implant is a treatment option that offers great functional and biologic advantages alongside noticeable long-term success outcomes with survival rates exceeding 95\% (Buser et al., 2012; van Velzen et al, 2015). Delayed implant placement has been widely and successfully used for replacing missing teeth (Tarazona et al., 2014). However, there are some challenges faced with delayed implant placement protocol due to the postextraction alveolar ridge resorption in buccolingual and apicocoronal directions (Van der Weijden et al., 2009 ; Vignoletti et al., 2012).

The percentage of the post-extraction horizontal and vertical dimensional changes are $29-63 \%$ and 11-22\% respectively (Tan et al., 2012). This is attributed to the disruption of vascular supply due to damage of periodontal ligament leading to pronounced bundle bone resorption (Chappuis et al., 2017). This pronounced post-extraction bone resorption usually leads to functional challenges and the need for augmentation procedures (Stumbras et al., 2019). In order to avoid such challenges, immediate post-extraction implant placement concept was introduced to avoid the bone resorption following tooth extraction and to reduce treatment time (Blanco et al., 2019). Immediate implant placement showed a high overall implant placement rate reaching $97.1 \%$ as reported in the systematic review conducted by Slagter et al., (2014) and $94.9 \%$ in the meta-analysis done by Cosyn et al., (2019).

Although immediate implant placement is effective in preservation of the alveolar bone dimensions but it fails to completely prevent the postextraction dimensional changes (Moy et al., 2016 ; Vignoletti et al., 2019). Therefore, attempts were done regarding placement of various biomaterials in the peri-implant gap to increase the immediate implant stability and to minimize or even prevent the post-extraction bone dimensional changes if possible. Multiple materials were successfully used such as bone grafting materials like xenografts
(Aly and Nassar 2016), autogenous grafts (Kabi et al., 2020) in addition to the application of bone morphogenetic proteins (BMPs) (Kim et al., 2012), platelet rich fibrin (PRF) (Medikeri et al., 2018).

Recently, other biomimetic agents have been used to induce bone formation, increase implant osseointegration, decrease post-extraction bone resorptive process and increase bone density which is consequently positively affecting implant success and survival rates (Rostom and Farouk 2020). Melatonin (MLT) and Hyaluronic acid (HA) are among these agents which are of a great interest for the recent researches whether in the medical or dental fields due to their confirmed physiological and structural functions, their biocompatibility and non-antigenic properties (Cristache et al., 2019).

MLT is a natural hormone with powerful antioxidant properties, released mainly the pineal gland (Martin et al., 2000; Klasbeek and Bujis 2002; Allegra et al., 2003). It is successfully used in various conditions as sleep disorders, cardiovascular, chronic inflammatory diseases and parkinsonism (Carpentieri et al., 2017)

MLT showed promising results in implant therapy leading to a shorter period for osseointegration and better implants stability (Maldonado et al., 2007). Rostom et al., (2016) showed that to MLT application around immediate- loaded implants led to significantly higher bone density and implant stability compared to implants placed without MLT. Moreover, Awwad et al., (2019) and Sun et al., (2019) reported that MLT accelerated new bone formation around the implants leading to an increase in the bone tissue ratio and bone to implant contact. This is justified by the pivotal role of MLT in enhancing of fibroblasts activity, osteoblasts differentiation and suppressing bone resorption (AlMughrabi et al., 2013; Montero et al., 2017; Permuy et al., 2017; Rostom and Farouk, 2020).

On the other hand, hyaluronic acid (HA) is a non- sulfated glycosaminoglycan which is a main component of the extracellular matrix of connective 
tissue found in most of body tissues as synovial fluid, vitreous humor, lungs, kidneys and muscle tissues (Ialenti and Di Rosa, 1994 ; Casale et al., 2016). It is found in abundant amount in periodontal and gingival tissues (Dahyia and Kamal 2013). HA has many chemical and physical properties such as high biocompatibility, viscoelasticity (Dahiya and Kamal 2013), anti-edematous effect (Jentesch et al., 2003) with remarkable anti-inflammtory and bacteriostatic actions (Xing et al., 2020). Therefore, HA has been widely applied as a therapeutic agent in different medical fields as in ophthalmic, rheumatologic, dermatologic (Necas et al., 2008). HA has been also successfully used in the dental field whether in periodontal therapy (Gontiya and Galgali 2012 ; Kumar et al., 2014 ; Yildirim et al., 2018) or with implant placement (de Araujo et al., 2007 ; Yazan et al., 2018). Francia and Ramirez (2019) in a mini-review article showed that HA have a positive effect on hard and soft tissue healing around immediate implants, accelerating osteogenic cell differentiation which enhanced implant osseointegration. On the other side, Yazan et al., (2019) showed that HA has no impact on bony tissue and does not induce new bone formation or enhance osteoid matrix content compared to spontaneous healing.

Since, it is well proven that both MLT and HA are having such a positive impact on improving the outcomes of implant therapy, this study aimed to investigate whether using the mixture of both agents together around post-extraction immediate implants would provide a synergistic effect or not especially that, to the best of our knowledge, no studies were conducted to evaluate the impact of such mixture on peri-implant hard tissue changes.

\section{SUBJECTS AND METHODS}

The study protocol followed the guidelines of the declaration of Helsinki (1975) revised in 2013 and was approved by the Ethics Committee of Scientific Research, Faculty of Dentistry, Cairo University.
All the steps were described in full details to each patient who participated in this study and each patient signed an informed consent.

This randomized, controlled clinical study was carried out on 24 patients (15 females and 9 males) with age range from 24-52 years. Subjects were selected from the clinic of Oral Medicine, diagnosis and Periodontology department, Faculty of Dentistry, Cairo University. Patients included in the study had non-restorable tooth or teeth in the interbicuspid area with adequate bone width and height (bone at least $3 \mathrm{~mm}$ apical to the socket most apical part), and proper inter-occlusal distance (8-10 mm) for dental implant placement. Patients who were compliant to follow strict oral hygiene measures. Following tooth extraction, an intact vestibular plate of bone was present following tooth extraction. Patients with any systemic disease that might contraindicate implant placement or any surgical procedures were excluded from the study. Heavy smokers (more than 10 cigarettes/day) and pregnant females were also excluded. Patients who received radiotherapy or chemotherapy during the past 12 months or having any parafunctional habits were not included in the present study.

\section{Allocation concealment and randomization}

Each experimental site was randomly assigned to either test (immediate implant with HA and MLT mixture) or control (immediate implant alone) group using computer generated randomization list with 1:1 allocation ratio. Allocation concealment was done using opaque sealed envelopes that were opened immediately before the surgical interventions. Patients were randomly assigned into two equal groups. This study was a single-blinded clinical trial. Blinding was for the outcome assessor and the statistician. It was impossible for both the operator and the patients to be blinded since the interventions were clearly different. 


\section{Sample size calculation:}

Based on the paper performed by (Granic et al., 2015), the expected difference using power $80 \%$ and $5 \%$ significance level, 9 patients were required in each group. This number was to be increased to a sample size of 12 patients in each group to compensate for any possible losses during follow up.

\section{Preoperative measures (for both groups)}

A full medical and dental history was taken and then intraoral examination with proper examination of the non restorsable tooth was done (Fig. 1) and periapical radiographs were taken at the time of the initial examination to confirm the diagnosis of the non-restorable tooth site.

All subjects received phase 1 periodontal therapy which consisted of supragingival scaling, subgingival debridement with proper mechanical and chemical plaque control (brushing twice daily and chlorhexidine $0.12 \%$ mouth wash* twice daily for 2 weeks). Restoration of any carious lesions and/or endodontic treatment of teeth adjacent to the implant site was done if needed. Cone beam computed tomography (CBCT) scan was done to record preoperative available bone dimensions measurements used to determine implant diameter, length and position.

\section{Surgical phase}

For both groups, all procedures were performed under local anesthesia (4\% articaine with 1/200 000 adrenaline solution). Atraumatic extraction of the targeted teeth was performed using periotome in a wedging action to preserve the alveolar bone integrity, then a small straight elevator was used to luxate the root if needed. A remaining root forceps was used to deliver the tooth or remaining root. The root and socket dimensions were measured after the extraction to be a guidance in implant size selection (Fig. 2; 3a, b). Irrigation of the socket with sterile saline solution was done followed by curettage of the socket walls to remove any granulation tissue. Then a periodontal probe was used to confirm the integrity of socket bony walls (Fig. 3c).

Implant* osteotomy was done through sequential drilling so that immediate implant engaged at least $3 \mathrm{~mm}$ of the bone apical to the extraction socket to achieve proper primary stability. The implant osteotomy was prepared more towards the palatal direction allowing for proper implant three dimensional prosthetically-driven positioning (Fig. 4b).

For the test group, MLT and HA mixture was prepared by mixing $1 \mathrm{cc}$ of prepared MLT gel with $1 \mathrm{cc}$ of HA gel. MLT gel was made from pure MLT powder ${ }^{* * *}$ prepared as $5 \%$ oral gel by mixing the MLT powder with propylene glycol $(1.2 / \mathrm{ml})$ to act as a carrier. While HA was used in the gel form 'Gengigel ${ }^{\circledast} \mathrm{HA}^{* * * *}$. The prepared mixture was added to the implant surface, into the extraction socket and in the peri-implant area using a sterile plastic syringe (Fig. 4a). For the control group, the implant was placed without any additions. Primary implant stability was checked and cover screw was placed, then criss-cross suture was performed to approximate the labial/buccal and lingual/palatal tissues (Fig. 4c). Immediate post-operative CBCT scans were done on the same day after implant placement, to check for proper implant position and for comparison of peri-implant bone dimensional changes at the end of the study.

\section{Postoperative care and follow up}

Patients were instructed to avoid any hard brushing and rinse with $0.12 \%$ Chlorhexidine mouth wash twice per day for two weeks. Brushing was resumed after sutures removal (10 days

\footnotetext{
* Hexitol, the arab drug company (ADCO) - Egypt

** NucleOss ${ }^{\mathrm{TM}}$, ŞANLILAR Tibbi Cihazlar Medikal Kimya San. Tic. Ltd. Şti. Turkey

*** Pure melatonin, Bulk supplements

**** Gengigel Gel®, 20ml, Ricerfarma, Milano, Italy
} 
postoperatively) at the treated sites using a soft tooth brush. Patients were then recalled every month to check on the healing of the surgical site and to ensure that they were following proper oral hygiene measures.

Six months after implantation, patients were recalled and $\mathrm{CBCT}$ scan was done to calculate the peri-implant bony changes. Implant exposure was then done and a healing cap was placed and interrupted sutures were done to stabilize the papilla around the healing cap

\section{Prosthetic phase}

After two weeks, healing caps were removed and impressions were taken for fabrication of the final implant supported porcelain- fused- to metal (PFM) crowns. Crowns were delivered after checking of occlusion and contour.

\section{Outcomes}

Peri-implant bone dimensional changes were radiographically evaluated comparing immediate

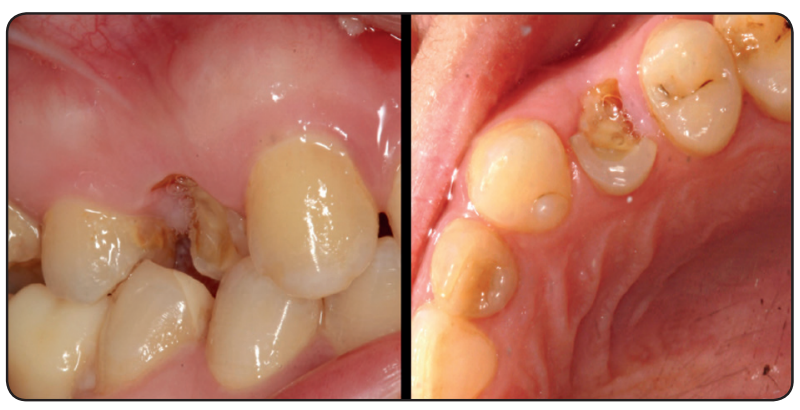

Fig. (1): Different views of non restorable upper right premolar

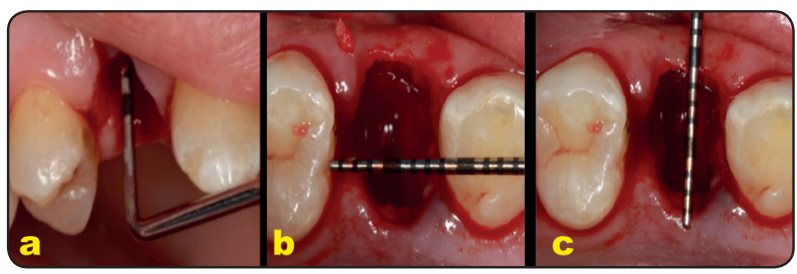

Fig. (3): (a) Checking socket bony walls integrity with a periodontal probe (b) Measurement mesiodistal and (c) buccolingual dimensions of the socket post-operative CBCT and 6 months postoperative CBCTs. The CBCT images in DICOM format (Digital Imaging and Communications in Medicine) were then imported. For each study subject, change in vertical facial bone height (VBH) and horizontal facial bone thickness (HBT) at 0, 2, 4, 6 apical to the implant platform, buccolingual bone width (BLW) were measured. Superimposition was done with auto registration to take the readings of changes between both CBTC scans. Bone density and its change was also measured by virtual superimposition method. This method allowed to use the bone density chart tool to obtain the readings of bone software to identify the bone density in layer of $2 \mathrm{~mm}$ thickness around the virtual implant simulating the real inserted implant in length and diameter ( typical and total simulation in all directions and angulations).

\section{Statistical analysis}

Data were analysed using IBM SPSS advanced statistics (Statistical Package for Social Sciences), version 24. Data were explored for normality

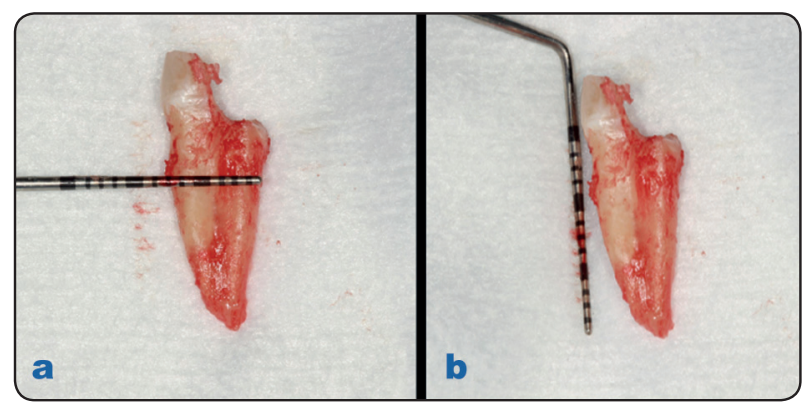

Fig. (2): Measuring root (a) width \& (b) length after atraumatic extraction,

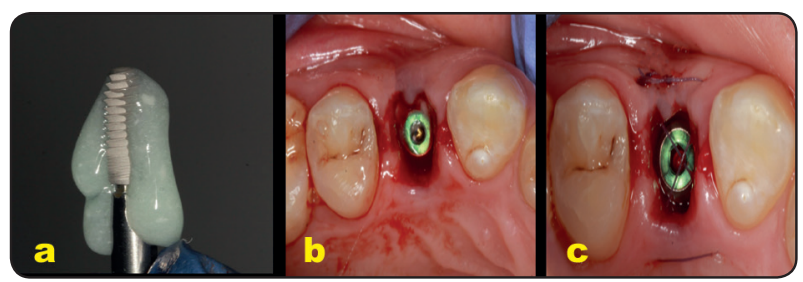

Fig. (4): (a) MLT and HA mixture injected around the implant fixture (b) Immediate implant placed in its proper position. (c) Suturing for approximation of buccal and palatal tissues after placement of healing cap 
using Kolmogorov-Smirnov test of normality. Parametric values were presented as mean and standard deviation (SD), and non parametric data were presented in median and range. Friedman test and Wilcoxon signed Rank test were used for intragroup comparison. Normally distributed values were compared using independent $t$ test between groups and paired $t$ test for intra-group comparison. Mann-Whitney U test was used for comparison of non normally distributed values. The significance level was set at $p \leq 0.05$

\section{RESULTS}

All the placed implants were clinically successful with no adverse events or postoperative complications in any of the 24 patients. No patients were lost to follow up and all of them completed the 6-months follow up period after implant placement.

\section{Demographic data:}

Mean age of patients in test group was $38.55 \pm 13.38$, while in control group it was $35.98 \pm 11.08$ with no statistical significant difference between both groups $(\mathrm{p}=0.43)$. Test group consisted of 8 females and 4 males, while control group consisted of 7 females and 5 males, with no significant difference between groups $(p=0.99)$ as shown in (Table 1).

Table (1): Descriptive statistics for the demographic data of the study groups

\begin{tabular}{ccccccc}
\hline & Group & $\begin{array}{c}\text { Test group } \\
(\mathbf{n}=\mathbf{1 2})\end{array}$ & $\begin{array}{c}\text { Control } \\
\text { group } \\
(\mathbf{n = 1 2})\end{array}$ & P-value \\
Variables & & & & & \\
\hline \multirow{2}{*}{$\begin{array}{c}\text { Age } \\
\text { (years) }\end{array}$} & Mean \pm SD & $38.55 \pm 13.38$ & $35.94 \pm 11.08$ & $0.43^{\text {ns }}$ \\
\cline { 1 - 5 } Gender & & $\mathbf{n}$ & $\mathbf{\%}$ & $\mathbf{n}$ & $\mathbf{\%}$ & \\
\cline { 2 - 6 } & Female & 8 & 66.7 & 7 & 58.3 & $0.99^{\text {ns }}$ \\
\cline { 2 - 5 } & Male & 4 & 33.3 & 5 & 41.7 & \\
\hline
\end{tabular}

Significance level P $\leq 0.05$; ns: non-significant

\section{Vertical buccal bone change:}

As presented in table (2) and fig. (5a), test group recorded lower mean value of vertical bone loss $(-0.97 \pm 0.265)$ compared to control group $(-1.08 \pm 0.275)$ with no statistical significance difference between both groups $(p=0.329)$

TABLE (2): Mean, SD and intergroup comparison of vertical bone loss of the studied groups

\begin{tabular}{ccccc}
\hline \multicolumn{2}{c}{ Test group A } & \multicolumn{2}{c}{ Control group } & \multirow{2}{*}{$\begin{array}{c}\text { Pvalue } \\
\text { (between groups) }\end{array}$} \\
\cline { 1 - 4 } Mean & SD & Mean & SD & \\
\hline-0.97 & 0.265 & -1.08 & 0.275 & 0.329 \\
\hline
\end{tabular}

Significance level $p \leq 0.05$

\section{Horizontal buccal bone thickness}

Control group recorded higher mean value of radiographic horizontal bone change compared to test group in all radiographic points except at point 6 . In point 0 , control group recorded mean decrease $(-0.41 \pm 0.371)$ versus test group $(-0.33 \pm 0.222)$. In point 2 , control group recorded mean decrease $(-0.48 \pm 0.39)$, in comparison to test group $(-0.45 \pm 0.233)$. In point 4 , control group recorded mean decrease $(-0.37 \pm 0.28)$ versus test group $(-0.29 \pm 0.165)$. In point 6 , test group recorded higher mean decrease $(-0.3 \pm 0.348)$, in comparison to control group $(-0.25 \pm 0.088)$, with no significant difference between groups $(\mathrm{P}=0.803),(\mathrm{P}=0.368)$ $(\mathrm{P}=0.694)(\mathrm{P}=0.543)$ at points $0,2,4,6$ respectively as shown in (Table 3 and Fig.5b)

\section{Buccolingual width}

In both groups, the mean BLW showed a statistically significant decrease after 6 months $(p=0.00)$ with a statistically significant difference between both groups only after 6 months ( $\mathrm{p}=0.035)$.

Test group recorded less mean decrease $(-2.08 \pm 0.996)$ with mean percentage change $(-27.84 \pm 11.39)$ versus control group $(-3.08 \pm 0.9)$ 
TABLE (3): Mean and SD values of difference and percentage change of radiographic horizontal bone change between the studied groups

\begin{tabular}{|c|c|c|c|c|c|c|}
\hline \multicolumn{2}{|c|}{$\begin{array}{l}\text { Radiographic horizontal bone } \\
\text { change }\end{array}$} & \multicolumn{2}{|c|}{$\begin{array}{l}\text { Group A } \\
\text { (Test) }\end{array}$} & \multicolumn{2}{|c|}{$\begin{array}{l}\text { Group B } \\
\text { (Control) }\end{array}$} & \multirow[t]{2}{*}{ P-value } \\
\hline & & Mean & SD & Mean & SD & \\
\hline \multirow{4}{*}{$\begin{array}{l}\text { Difference from } \\
\text { Immediate post-op. to } \\
6 \text { months }\end{array}$} & P0 & -0.33 & 0.222 & -0.41 & 0.371 & 0.543 \\
\hline & $\mathrm{P} 2$ & -0.45 & 0.233 & -0.48 & 0.391 & 0.803 \\
\hline & $\mathrm{P} 4$ & -0.29 & 0.165 & -0.37 & 0.28 & 0.368 \\
\hline & P6 & -0.3 & 0.348 & -0.25 & 0.088 & 0.694 \\
\hline \multirow{4}{*}{$\begin{array}{l}\text { Percent change } \\
\text { from Immediate post- } \\
\text { op. to } 6 \text { months }\end{array}$} & P0 & -19.47 & 11.26 & -21.19 & 15.58 & 0.760 \\
\hline & $\mathrm{P} 2$ & -27.05 & 16.66 & -26.72 & 18.42 & 0.964 \\
\hline & P4 & -21.3 & 14.05 & -25.53 & 12.13 & 0.439 \\
\hline & P6 & -23.86 & 22.82 & -29.63 & 8.01 & 0.423 \\
\hline
\end{tabular}

Significance level $p \leq 0.05$

TABLE (4): Mean and standard deviation values of buccolingual width, the difference and percentage change in the studied groups

\begin{tabular}{cccccc}
\hline & \multicolumn{2}{c}{$\begin{array}{c}\text { Group A } \\
\text { (Test) }\end{array}$} & \multicolumn{2}{c}{$\begin{array}{c}\text { Group B } \\
\text { (Control) }\end{array}$} & $\begin{array}{c}\text { Pvalue } \\
\text { (between } \\
\text { groups) }\end{array}$ \\
\cline { 2 - 6 } & Mean & SD & Mean & SD & $0.871^{\mathrm{ns}}$ \\
\hline Immediate Post-op. & $7.42^{\mathrm{a}}$ & $1.31^{\mathrm{a}}$ & 7.50 & 1.17 & $0.035^{*}$ \\
\hline 6 months & $5.33^{\mathrm{b}}$ & $1.15^{\mathrm{b}}$ & 4.42 & 0.79 & $0.017^{*}$ \\
\hline Difference & -2.08 & 0.996 & -3.08 & 0.90 & $0.005^{*}$ \\
\hline Percentage change & -27.84 & 11.39 & -40.77 & 8.597 & 0.79 \\
\hline
\end{tabular}

Significance level $p \leq 0.05$, Statistically significant. Different letters mean significant difference within same group.

with percentage change $(-40.77 \pm 8.597)$, with a 6 months post-operatively, the mean bone density statistically significant difference between groups in test group was $623.1 \pm 128.38$, compared to $(\mathrm{P}=0.017)$ and $(\mathrm{P}=0.005)$ respectively as shown in $591.60 \pm 120.73$ in control group. The difference not (Table 4 and Fig.6a).

\section{Bone density}

The mean bone density immediate post- recorded in mean bone density after 6 months postoperatively in test group was $564.20 \pm 114.82$, operative in each group separately $(\mathrm{p}=0.00 ; \mathrm{p}=0.00)$ compared to $569.40 \pm 113.21$ in control group. After as shown in table (5) 
The median change between immediate postoperative and after 6 months in bone density in test group was 58.45 (range 8-110), compared to 18.1 (range 0-70) in control group. The difference was statistically significant $(\mathrm{p}=0.005)$. The median percentage change in bone density in test group was 10.44 (range 1.88-19.47), compared to 2.99 (range 09.97) in control group with a statistically significant difference between both groups ( $\mathrm{p}=0.006$ ) as shown in table (6) and fig. (6b)

TABLE (5) Mean, standard deviation (SD) and inter and intragroup comparison of bone density of the studied groups at baseline and after 6 months

\begin{tabular}{lccccc}
\hline \multirow{2}{*}{ Bone density } & \multicolumn{2}{c}{ Test group } & \multicolumn{2}{c}{ Control group } & P value \\
\cline { 2 - 5 } & Mean & S.D. & Mean & S.D. & 0.912 \\
\hline Immediate postoperative & 564.20 & 114.82 & 569.40 & 113.21 & 0.542 \\
\hline After 6 months & 623.10 & 128.38 & 591.60 & 120.73 & \\
\hline P value & \multicolumn{3}{c}{$0.00^{*}$} & \multicolumn{3}{|c}{$0.004 *$} \\
\hline
\end{tabular}

Significance level $p \leq 0.05$, *significant

TABLE (6): Mean, standard deviation (SD), median and range of difference and percentage change of bone density from baseline to 6 months postoperatively in the studied groups

\begin{tabular}{lccccc}
\hline \multirow{2}{*}{ Bone density } & \multicolumn{2}{c}{ Test group } & \multicolumn{2}{c}{ Control group } & \multirow{2}{*}{ P value } \\
\cline { 2 - 5 } & Median & $($ Min - Max) & Median & (Min - Max) & \\
\hline Difference & 58.45 & $(8-110)$ & 18.1 & $(0-70)$ & $0.005^{*}$ \\
\hline Percentage change $(\%)$ & 10.44 & $(1.88-19.47)$ & 2.99 & $(0-9.97)$ & $0.006^{*}$ \\
\hline
\end{tabular}

Significance level $p \leq 0.05$, *significant

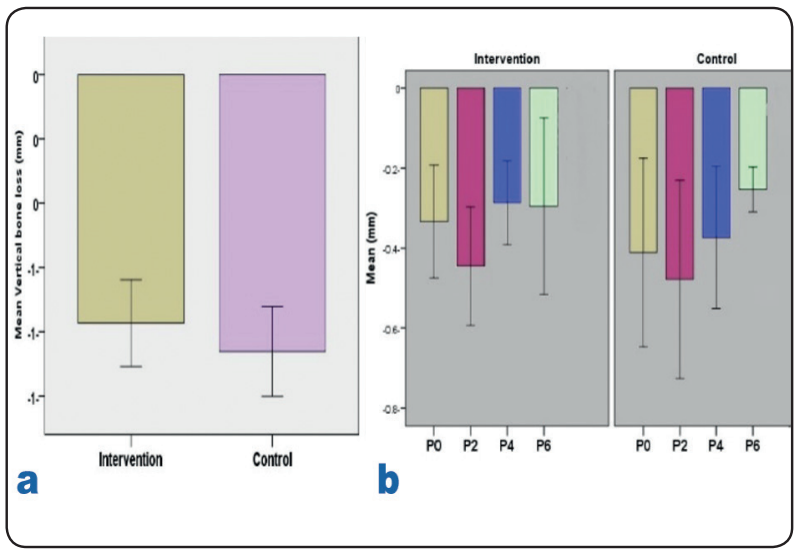

Fig. (5): Bar chart illustrating (a) Mean radiographic vertical bone loss in both groups. (b) Mean change in radiographic horizontal buccal bone thickness in both groups

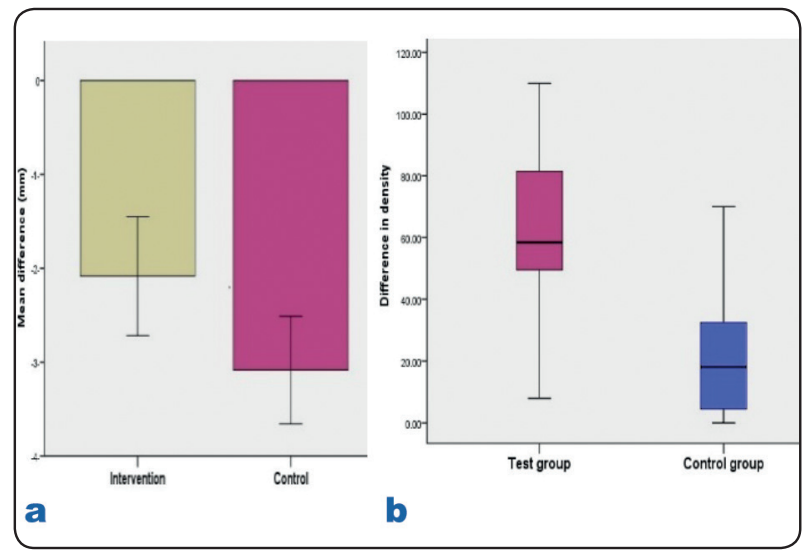

Fig. (6): (a) Bar chart illustrating mean change in buccolingual width in both groups. (b) Box plot illustrating median change in bone density after 6 months in both groups. 


\section{DISCUSSION}

Immediate post-extraction implantation has become an increasingly interesting strategy for replacing hopeless teeth to counteract the postextraction dimensional bone changes, reduce the overall treatment time and improve esthetic outcomes. (Chen et al., 2009; Ortega- Martinez et al., 2012). Several studies have concluded that placing biomaterials in the extraction sockets may help bone remodeling and decrease the marginal ridge resorption (Thakkar et al., 2016 ; Reda et al., 2020). Since both HA and MLT are powerful biomimetic agents with good properties that may promote soft tissue, bone healing and implant osseointegration, so the resulting mixture of both materials may offer additive benefit as a therapeutic agent (Cristache et al., 2018). The rationale of this study was to evaluate whether MLT and HA mixture around immediately placed implants has a beneficial synergistic effect on peri-implant bone changes, and quality.

To the best of our knowledge, no clinical trials were conducted to evaluate the effect of HA and MLT mixture application around immediately placed implants on peri-implant bone dimensional changes, bone density. Trials have only discussed the effect of one of the two materials alone on implant procedure especially MLT..

Regarding vertical dimensional changes, the current study showed no statistical significant difference between both groups with mean (-0.97 ; $-1.08 \mathrm{~mm}$ ) for test and control groups respectively. This is in agreement with the results recorded by Awwad et al., (2019) who evaluated the crestal bone loss around immediate implants after addition of beta tricalcium phosphate with and without MLT. The mean crestal bone loss after 6 months was $(0.41$ ; $0.43 \mathrm{~mm}$ ) in test and control groups respectively with no statistical significant difference between them. In addition, Yasser et al., (2020), found no significant difference in buccal (mesial and distal aspects) bone level reduction when comparing the two groups after 6 months from implant placement with and without MLT application.

On the contrast, Hazaa et al., (2017) and (2020) evaluated the impact of adding MLT to autogenous bone graft around immediate and delayed implants respectively. In 2017, they reported a statistically significant difference in the mean of marginal bone loss between the control group $(1.91 \mathrm{~mm})$ and the test group $(0.84 \mathrm{~mm})$ in favor of the latter. This disparity might be explained by the longer follow up in their study which was 9 months. In 2020, they recorded a statistical significant difference in marginal bone loss test group $(0.67 \mathrm{~mm})$ and control group $(1.66 \mathrm{~mm})$ in favor of the test group. This can be attributed to the different implant placement protocol used since the implant were placed after socket complete healing; at least 8 weeks after extraction.

As for radiographic horizontal bone dimensional alterations, the present study showed that the test group recorded lower mean value of radiographic buccal bone thickness change compared to control group in most of radiographic points. The control group recorded more buccal bone resorption 0.41 $\mathrm{mm}(21.19 \%)$ than that of the test group $0.33 \mathrm{~mm}$ $(19.47 \%)$ at implant platform level (Point 0) six months after implant placement, with no statistically significant difference between groups.

These findings come in accordance to what (Alcantara et al., 2018) found in their study to evaluate the HA effect on repair of extraction sockets. They reported no significant difference between test (HA addition) and control groups (healing without adding HA) with mean bone loss in the cervical, middle, and apical thirds 0.71, 0.25, and 0.19 for test sockets and $0.75,0.54$, and 0.21 for the control sockets respectively. Furthermore, our study results are in agreement with the split mouth study conducted by (Yasser et al., 2020) evaluating thickness of buccal cortical plate with and without 
the application of MLT. The results showed less mean reduction of buccal bone plate for test group $(0.116 \mathrm{~mm})$ than control group $(0.185 \mathrm{~mm})$ with no statistically significant difference between both groups.

However, the present study results reported a statistically significant difference in the change of buccolingual bone width from baseline to 6 months post-operatively between test and control groups with means $(-2.08 \mathrm{~mm} ;-3.08 \mathrm{~mm})$ respectively in favor of the test group. This indicates that the application of MLT and HA mixture led to a considerable reduction in both buccal and palatal bone resorption that occurred in control group, leading to this statistically less buccolingual bone width reduction after 6 months.

Regarding bone density, test group recorded a higher mean (623.10) than the control group (591.60) after 6 months postoperatively with change in bone density from baseline [median 58.45 (range 8 - 110), median=18.1 (range 0 - 70)] respectively. This difference was statistically significant in favor of the test group. This is consistent to what AbdelDayem, et al., (2014) reported after evaluating bone density 6 months after implant placement with the application of Cerasorb with and without MLT. They recorded a statistically significant difference between the 2 groups in favor of the MLT group at 1 and 6 months. Moreover, Hazaa et al., (2017), showed a statistical significant difference in bone density when adding MLT to autograft around immediate implants with mean change 384.35 (control) versus 420.65 (test) respectively 6 months after implant placement.

Furthermore, Rostom et al., (2019) investigated the effect of MLT application around short implants supporting removable partial dentures. There was a statistical increase in bone density after 6 months with mean percentage change (4.1 vs 3.6) with and without MLT respectively. The ability of MLT to significantly increase bone density could be attrib- uted to its antioxidant properties and to its role in increasing the production and activity of alkaline phosphatase. It also upregulates production of type I collagen, osteopontin, osteoprotegrin, sialoprotein which significantly promotes osteoblasts differentiation, maturation and proliferation (Radio et al., 2006 ; Kazuhito et al., 2008). Furthermore, MLT inhibits bone resorption via scavenging reactive oxygen species and suppressing of osteoclast differentiation by downregulating of receptor activator of nuclear factor kappa (RANK) expression (Nakano et al., 2019).

On the other hand, Awwad et al., (2019) recorded no statistical significant difference in mean bone density between test $(\beta$-TCP + MLT) and control groups $(\beta-\mathrm{TCP})$ around immediate implants after 6 months with mean $(1158.28 ; 1081.70)$ respectively. Furthermore, Hazaa et al., (2020) reported a higher mean bone density in test group (autograft + MLT) than control group (autograft only) [582.80; 649.33] respectively after 6 months but the difference was statistically insignificant. This might be justified by the different protocol of implant placement used by Hazaa et al., (2020) which was delayed implant placement in healed bony sites.

Lastly, from the results of the current study and comparing them to those of the previously mentioned studies, it can be mentioned that most of this mixture's beneficial impact is attributed mainly to the MLT which has a direct effect on bone remodeling, while HA main benefit is promoting and accelerating soft tissue healing.

\section{CONCLUSION}

Within the limitations of the present study, we may conclude that local application of HA and MLT mixture minimized the peri-implant hard tissue dimensional changes around immediate postextraction implants in terms of reduction of buccal vertical and horizontal bone changes and increase of bone density. However, this was statistically 
significant only in the increase of bone density and decrease in buccolingual resorption. Further studies with longer follow up are recommended with the evaluation of soft tissue healing to investigate the beneficial effect of HA in such mixture.

\section{REFERENCES}

- Abdel-Dayem, H., Abdel-Alim, H., \& Banasr, F. (2014). Topical application of MLT around immediate implants. American Journal of Research Communication, 2(3), 1-12.

- Alcântara, C., Castro, M., Noronha, M. S., Martins-Junior, P. A., Mendes, R. M., Caliari, M. V., Mesquita, R. A., \& Ferreira, A. J. (2018). HA accelerates bone repair in human dental sockets: a randomized triple-blind clinical trial. Brazilian oral research, 32, e84.

- Allegra M, Reiter RJ, Tan DX, Gentile C, Tesoriere L and Livrea MA (2003). The chemistry of MLT's interaction with reactive species. J Pineal Res; 34(1): 1-10.

- Almughrabi OM, Marzouk KM, Hasanato RM and Shafik SS (2013). MLT levels in periodontal health and disease. J Periodontal Res; 48(3): 315-321.

- Aly, Lobna. and Nassar, Hossam (2016). Outcome of immediate implant placement with bone augmentation in the anterior maxillary supporting partial denture. Journal of Dental Implants; 6 (1): 13-21

- $\quad$ Awwad, Y. M., Khalil, M. A., \& Al Sayed, S. A. (2019). Effect of MLT application around immediate implants. AlAzhar Journal of Dental Science, 22(2-183), 187.

- Blanco J, Carral C, Argibay O and Liñares A (2019). Implant placement in fresh extraction sockets. Periodontol 2000; 79(1): 151-167

- Buser D, Janner SF, Wittneben JG, Brägger U, Ramseier CA and Salvi GE (2012). 10- year survival and success rates of 511 titanium implants with a sandblasted and acid-etched surface: a retrospective study in 303 partially edentulous patients. Clin Implant Dent Relat Res; 14(6): 839-851.

- Casale M, Moffa A, Vella P, Sabatino L, Capuano F, Salvinelli B, Lopez MA, Carinci F and Salvinelli F (2016). HA: Perspectives in Dentistry. A Systematic Review. Int J Immunopathol Pharmacol; 29(4): 572-582.

- Carpentieri AR, Lopez MEP, Aguilar J and Sola VM (2017). MLT and periodontal tissues: Molecular and clinical perspectives. Pharmacol Res; 125(Pt B): 224-231.

- Chappuis V, Araújo MG and Buser D (2017). Clinical relevance of dimensional bone and soft tissue alterations post-extraction in esthetic sites. Periodontol 2000; 73(1): 73-83.

- Chen ST, Beagle J, Jensen SS, Chiapasco M and Darby I (2009). Consensus statements and recommended clinical procedures regarding surgical techniques. Int $\mathrm{J}$ Oral Maxillofac. Implants; 24: 272-278.

- Cosyn, J., De Lat, L., Seyssens, L., Doornewaard, R., Deschepper, E., \& Vervaeke, S. (2019). The effectiveness of immediate implant placement for single tooth replacement compared to delayed implant placement: A systematic review and meta-analysis. Journal of clinical periodontology, 46 Suppl 21, 224-241.

- $\quad$ Cristache, C. M., Totu, E. E., Cristache, G., Nechifor, A. C., \& Pintilie, I. I. (2019). MLT and HA in Periodontal Disease. REVISTA DE CHIMIE, 70(3), 1089-93.

- Cristache, C. M., Totu, E. E., Petre, D., Buga, R., Cristache, G., \& Totu, T. (2018). MLT and HA mixture as a possible therapeutic agent in dental medicine. Rev. Chim.Bucharest, 69, 1996-1999.

- Dahiya P and Kamal R (2013). HA: A boon in periodontal therapy. North American Journal of Medical Science; 5(5): 309-315

- De Araújo Nobre M, Cintra N and Maló P (2007). Peri-implant maintenance of immediate function implants: A pilot study comparing HA and chlorhexidine. Int J Dent Hyg; 5(2): 87-94.

- $\quad$ El-Gammal, M. Y., Salem, A. S., Anees, M. M., \& Tawfik, M. A. (2016). Clinical and radiographic evaluation of immediate loaded dental implants with local application of MLT: a preliminary randomized controlled clinical trial. Journal of Oral Implantology, 42(2), 119-125.

- Francia Carolina and Ramirez Hernandez. "Use of HA in Osteointegration of Dental Implants". Scientific Archives Of Dental Sciences 2.10 (2019): 27-28.

- Gontiya G and Galgali SR (2012). Effect of hyaluronan on periodontitis: A clinical and histological study. J Indian Soc Periodontol; 16(2): 184-192

- Granic, Marko et al. 2015. "Implant Stability Comparison of Immediate and Delayed Maxillary Implant Placement by Use of Resonance Frequency Analysis--a Clinical Study." Acta clinica Croatica 54(1): 3-8. 
- Hazzaa HHA, El-Kilani NS, Elsayed SA, Abd El Massieh PM. Evaluation of Immediate Implants Augmented with Autogenous Bone/MLT Composite Graft in the Esthetic Zone: A Randomized Controlled Trial. J Prosthodont. 2019 Feb; 28 (2): e637-e642.

- Hazzaa H. \& Shawki N. \& El-Aziz, L. (2020). Early loading of Dental implant grafted with Autgenous Bone Graft Alone or Combined with MLT Gel: A Randomized Clinical Trial. Austin J Dent 7(2): id1137 - Page 1-6.

- $\quad$ Ialenti A and Di Rosa M (1994). HA modulates acute and chronic inflammation. Agents and Actions; 43(1-2): 44-47

- Jentsch H, Pomowski R, Kundt G and Göcke R (2003). Treatment of gingivitis with hyaluronan. J Clin Periodontol; 30(2): 159-164.

- $\quad$ Kabi S, Kar R., Samal D, Deepak K. C., Kar, I. B., \& Mishra, N. (2020). Immediate dental implant placement with or without autogenous bone graft: A comparative study. National journal of maxillofacial surgery, 11(1), 46-52.

- Kalsbeek A and Buijs RM (2002). Output pathways of the mammalian suprachiasmatic nucleus: coding circadian time by transmitter selection and specific targeting. Cell Tissue Res; 309(1): 109-118

- Kazuhito S, Satoru T, Reiko T (2008). MLT at pharmacological doses enhances human osteoblastic differentiation in vitro. J Pineal Res; 44: 387-96.

- $\quad$ Kaya, O. A., Muglali, M., Torul, D., \& Kaya, I. (2019). Peri-implant bone defects: A 1-year follow-up comparative study of use of HA and xenografts. Nigerian journal of clinical practice, 22(10), 1388-1395.

- Kim, B. J., Kwon, T. K., Baek, H. S., Hwang, D. S., Kim, C. H., Chung, I. K., ... \& Shin, S. H. (2012). A comparative study of the effectiveness of sinus bone grafting with recombinant human bone morphogenetic protein 2-coated tricalcium phosphate and platelet-rich fibrin-mixed tricalcium phosphate in rabbits. Oral surgery, oral medicine, oral pathology and oral radiology, 113(5), 583-592.

- Kumar, R., Srinivas, M., Pai, J., Suragimath, G., Prasad, K., \& Polepalle, T. (2014). Efficacy of HA (hyaluronan) in root coverage procedures as an adjunct to coronally advanced flap in Millers Class I recession: A clinical study. Journal of Indian Society of Periodontology, 18(6), 746.

- Maldonado MD, Murillo-Cabezas F, Terron MP, Flores LJ, Tan DX, Manchester LC and Reiter RJ (2007). The potential of MLT in reducing morbidity-mortality after craniocerebral trauma. J Pineal Res; 42(1): 1-11.
- Martin M, Macias M, Escames G, León J and Acuña-Castroviejo D (2000). MLT but not vitamins C and E maintains glutathione homeostasis in t-butyl hydro-peroxide induced mitochondrial oxidative stress. FASEB J; 14(12): $1677-1679$

- $\quad$ Medikeri, R. S., Meharwade, V., Wate, P. M., \& Lele, S. V. (2018). Effect of PRF and Allograft Use on Immediate Implants at Extraction Sockets with Periapical InfectionClinical and Cone Beam CT Findings-. The Bulletin of Tokyo Dental College, 59(2), 97-109.

- Montero, J., López-Valverde, N., Ferrera, M. J., \& LópezValverde, A. (2017). Changes in crevicular cytokines after application of MLT in patients with periodontal disease. Journal of clinical and experimental dentistry, 9(9), e1081e1087.

- Moy, Peter \& Nishimura, Grant \& Pozzi, Alessandro \& Danda, Anil. (2016). Single implants in dorsal areas - A systematic review. European Journal of Oral Implantology. 9. 163-172.

- Nakano M, Ikegame M, Igarashi-Migitaka J (2019). Suppressive effect of MLT on osteoclast function via osteocyte calcitonin. J. Endocrinol 242:13-23.

- Necas J, Bartosikova L, Brauner P and Kolar J (2008). HA (hyaluronan): a review. Veterinarni Medicina; 53(8): $397-$ 411.

- Ortega-Martínez J, Pérez-Pascual T, Mareque-Bueno S, Hernández-Alfaro F and Ferrés-Padró E (2012). Immediate implants following tooth extraction. A systematic review. Med Oral Patol Oral Cir Bucal; 17(2): e251-e261.

- Permuy M, López-Peña M, González-Cantalapiedra A and Muñoz F (2017). MLT: A Review of Its Potential Functions and Effects on Dental Diseases. Int J Mol Sci; 18(4): 865-872.

- $\quad$ Reda, Amr, Gaber, Hala, Ali, Shaimaa and Amr, Ahmed (2020). "Pure collagen cone versus collagen cone blended with gentamicin in alveolar ridge preservation following extraction of chronic infected tooth" A randomized histological and clinical study. Egyptian Dental Journal; 66: 2271-2288

- $\quad$ Radio NM, Doctor JS, Witt-Enderby PA (2006). MLT enhances alkaline phosphatase activity in differentiating human adult mesenchymal stem cells grown in osteogenic medium via MT2 MLT receptors and the MEK/ERK (1/2) signaling cascade. J Pineal Res 40:332-342. 
- $\quad$ Rostom, D., \& Faroukabdulla, M. (2020). MLT Effect on Short Implant Supporting Kennedy Class I Removable Partial Denture in Atrophied Posterior Mandibular Alveolar Ridge. Advanced Dental Journal, 2(2), 51-60.

- $\quad$ Rostom, Doaa, Ela, Alaa and Abdalla, Mohamed (2016). Effect of MLT on osseointegration of immediate loading implant supported mandibular over denture: Randomized clinical trial. International Dental \& Medical Journal of Advanced Research, 2: 1-5.

- $\quad$ Slagter, K. W., den Hartog, L., Bakker, N. A., Vissink, A., Meijer, H. J., \& Raghoebar, G. M. (2014). Immediate placement of dental implants in the esthetic zone: a systematic review and pooled analysis. Journal of periodontology, 85(7), e241-e250.

- Stumbras, A., Kuliesius, P., Januzis, G., \& Juodzbalys, G. (2019). Alveolar Ridge Preservation after Tooth Extraction Using Different Bone Graft Materials and Autologous Platelet Concentrates: A Systematic Review. Journal of oral \& maxillofacial research, 10(1), e2.

- $\quad$ Sun, T., Li, J., Xing, H. L., Tao, Z. S., \& Yang, M. (2020). MLT improves the osseointegration of hydroxyapatitecoated titanium implants in senile female rats. Zeitschrift für Gerontologie und Geriatrie, 53(8), 770-777.

- Tan WL, Wong TL, Wong MC and Lang NP (2012). A systematic review of post-extractional alveolar hard and soft tissue dimensional changes in humans. Clin Oral Implants Res; 23(5): 1-21.

- Tarazona B, Tarazona-Álvarez P, Peñarrocha-Oltra D and Peñarrocha-Diago MA (2014). Relationship between indication for tooth extraction and outcome of immediate implants: a retrospective study with 5 years of follow-up. J Clin Exp Dent; 6(4): e384-388.

- Thakkar, DhavalJ \& Deshpande, Neeraj \& Dave, DeepakH \& Narayankar, SurajD. (2016). A comparative evaluation of extraction socket preservation with demineralized freeze-dried bone allograft alone and along with plateletrich fibrin: A clinical and radiographic study. Contemporary Clinical Dentistry; 7 (3): 371-376.

- Van der Weijden F, Dell'Acqua F, Slot DE. Alveolar bone dimensional changes of post-extraction sockets in humans: a systematic review. J Clin Periodontol 2009; 36: 1048-1058.

- $\quad$ van Velzen, F. J., Ofec, R., Schulten, E. A., \& Ten Bruggenkate, C. M. (2015). 10-year survival rate and the incidence of peri-implant disease of 374 titanium dental implants with a SLA surface: a prospective cohort study in 177 fully and partially edentulous patients. Clinical oral implants research, 26(10), 1121-1128.

- Vignoletti F, Johansson C, Albrektsson T, De Sanctis M, San Roman F and Sanz M (2009). Early healing of implants placed into fresh extraction sockets: an experimental study in the beagle dog. De novo bone formation. J Clin Periodontol; 36(3): 265-277.

- Vignoletti, F., Sanz-Esporrin, J., Sanz-Martin, I., Nuñez, J., Luengo, F., \& Sanz, M. (2019). Ridge alterations after implant placement in fresh extraction sockets or in healed crests: An experimental in vivo investigation. Clinical oral implants research, 30(4), 353-363.

- $\quad$ Xing, Fei \& Zhou, Changchun \& Hui, Didi \& Du, Colin \& Wu, Lina \& Wang, Linnan \& Wang, Wenzhao \& Pu, Xiaobing \& Gu, Linxia \& Liu, Lei \& Xiang, Zhou \& Zhang, Xingdong. (2020). HA as a bioactive component for bone tissue regeneration: Fabrication, modification, properties, and biological functions. Nanotechnology Reviews; 9 (1): 1059-1079.

- Yasser Z., Abdulkareem A., Saliem S. Effect of Topical MLT Application on the Peri-Implant Proximal Bone Level and Cortical Plate Thickness (Pilot Clinical Trial) J Res Med Dent Sci, 2020, 8 (7):394-399

- Yazan M, Kocyigit ID, Atil F, Tekin U, Gonen ZB, Onder ME (2019). Effect of hyaluronic acid on the osseointegration of dental implants. Br J Oral Maxillofac Surg. Jan;57(1):53-57.

- Yazan, Mürüde, Kocyigit, ismail doruk, Atil, Fethi, Tekin, Umut, Gonen, Zeynep and Onder, Ercument. (2018). Effect of HA on the osseointegration of dental implants. Br J Oral and Maxillofac Surg.; 57 (1): 53-57.

- $\quad$ Yıldırım, S., Özener, H. Ö., Doğan, B., \& Kuru, B. (2018). Effect of topically applied HA on pain and palatal epithelial wound healing: An examiner-masked, randomized, controlled clinical trial. J Periodontol.; 89 (1): 36-45. 